\title{
PSYCHOLOGICAL CHARACTERISTICS OF THE VALUE ORIENTATION SYSTEM OF ARMENIANS IN TITLE ETHNOS AND RUSSIAN DIASPORA
}

\author{
Dr. Irina Abakumova, Pedagogy, Psychology and Defectology Faculty, Don State Technical University, Rostov- \\ on-Don, Russia \\ E-mail: abakira@mail.ru \\ Dr. Asya Berberyan, Department of Psychology, Russian-Armenian (Slavonic) University, Yerevan, Armenia \\ E-mail: aspsy@inbox.ru \\ Dr. Hermine Berberyan, University of Groningen, Institute of Artificial Intelligence and Cognitive Engineering, \\ Groningen, Netherlands \\ E-mail: hermpsy@mail.ru
}

\section{A R T I C LE INF O \\ Original Research \\ Received: July, 19.2019. \\ Revised: August, 12.2019. \\ Accepted: August, 17.2019. \\ doi:10.5937/IJCRSEE1902011A \\ UDK \\ $316.644-057.875: 316.752(=161.1)$ \\ $316.644-057.875: 316.752(=19)$}

Keywords:

system of value orientations,

Armenian ethnos,

psychological aspects,

title ethnos,

diaspora,

identity.

\section{A B S T R A C T}

The article substantiates the importance and relevance of studies on ethnic identity and value orientations, since they predetermine the assimilation of the spiritual culture of society, the formation of value orientations significantly contributes to the development of the individual. For that goal, a study was conducted with 160 bachelor and master students (ethnic Armenians and Russians living in Russia and Armenia) with a use of Twenty Statements Test and Schwartz's Value Survey. The results of the study allowed us to describe common characteristics of the value-semantic aspect of the ethnic identity in Armenian and Russian title ethnos and diaspora. Thus, we aimed to describe of the process of identifying and assigning the values in Armenians as a dual process: the acceptance of values, the norms of the group with which a person is identified; the comparison of himself and his group with others, which has a positive impact on the cohesion of his group.

(C) 2019 IJCRSEE. All rights reserved.

\section{INTRODUCTION}

The study of value orientations is relevant nowadays, since they influence the assimilation of the spiritual culture of society. Value orientations are responsible for the transformation of cultural values into motives and incentives for the actions of people. Consequently, the formation of value orientations contributes to the development of personality. The term "orientation" is used in many sciences, in psychology it has at least two mean-

Corresponding Author

Dr. Hermine Berberyan, University of Groningen, Institute of Artificial Intelligence and Cognitive Engineering, Groningen, Netherlands

E-mail: hermpsy@mail.ru

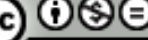

This work is licensed under a Creative Commons Attribution - NonCommercial - NoDerivs 4.0. The article is published with Open Access at www.ijcrsee.com ings: it describes the process and the result. Orientation as a process includes projective actions, from planning to the final result. It is the choice of goals, methods for achieving them, the assessment of the accuracy of actions and the comparison of actions with the plans, orientation and life values of the individual. Typically, by orientation as a result we mean mastering a wide range of knowledge and it assumes that the level acquired by a person is a kind of basis for continuous search and finding, deepening and improving ideas and knowledge. In this case, orientation implies a certain emotional state of confidence in the loyalty of the chosen direction of the plan, thought and action. Orientation is the process of personal development, where the development, change and inclusion of its components gradually leads to high integrity. The accumulation of formation components, their reorganization and preservation, separation of functions, integration and hierarchy provide the opportunity for the emergence of 
Abakumova, I., Berberyan, A. \& Berberyan, H. (2019). Psychological characteristics of the value orientation system of Armenians in title ethnos and Russian diaspora, International Journal of Cognitive Research in Science, Engineering and Education (IJCRSEE), 7(2), 11-17

new structural components and new functions of the value image of the world, the image of "Self", the image of the future.

At present, civilizational processes allow us to make conclusions not only about the internationalization of ethnic groups, but also about ethnic isolation, encapsulation, the desire to isolate from other ethnic groups (Stefanenko and Kupavskaya, 2010; Tajfel, 2010; Waterman, 1982). However, there are ethnic groups that develop in two planes, the hypostases: in the conditions of residence in the title ethnos and in diaspora. The relevance of the study lies in the importance of studying the ethnic identity characteristics of Armenians residing on their territory and in conditions of migration. Armenia and Russia have historically been closely interconnected in the economic, socio-cultural, and spiritual spheres of living, despite the absence of geographic connectivity. Historical traditions were brought together and based on living in a single state, the USSR. In recent decades, the processes of migration flows, in particular, to Russia, have intensified, which actualizes the need to study the characteristics of ethnic identity, self-consciousness and the mentality of ethnic groups (Berberyan and Berberyan, 2016).

It should be noted that the ongoing modernization of most communities, the evergrowing share of mass culture, ethno-political integration, deep transformation of political and public life, are of interest to the problem of forming the identity of the modern generation, preserving the components of national identity and value-sense aspects of ethnic identity (Lebedeva, Tatarko and Berry, 2016; Soldatova and Geer, 2013).

The goal of the study is to identify the psychological characteristics of the value orientation system of ethnic Armenians in title ethnos and the diaspora.

The hypothesis of the study is the following: we assume that the normative and value foundations of the ethnocultural tradition and the features of self-understanding of ethnicity and the value structure are different in Armenians residing in title ethnos as compared to the ones residing in diaspora.

Value orientations are a complex multistage formation in which 3 main components are distinguished: emotive, cognitive, and behavioral. Emotive - the emotional aspect arising from the assessment; cognitive is an element of knowledge and, finally, behavioral - is associated with the implementation of value orientations in the behavior of the individual. Consequently, it is impossible to study value orientations only with one method, since it is well known that a verbally expressed position of a person in relation to certain cultural values does not always coincide with his real behavior. Based on the main spheres of human social life, there are three groups of values: material, socio-political and spiritual. Material values are valuable objects and objects, namely the means of labor and things of consumption. Natural values should include natural benefits that are enclosed in natural wealth. Object values include objects of the material world created by human efforts and objects of the cultural heritage of previous years.

Socio-political values are the values of political and social events, phenomena, political actions and acts. Socio-political values include social welfare, which is contained in social and political movements and the progressive significance of historical events that contribute to the prosperity of society, cooperation among nations, and the strengthening of peace in general. Spiritual values are the normative and evaluative side of the phenomena of public consciousness and are expressed in the appropriate form (Berberyan and Berberyan, 2016). Spiritual values are considered to be the values of art, philosophy, science, morality and law.

Despite their differences, spiritual, material, and sociopolitical values are inter-related, and in each species there is an aspect of a different kind of values. In addition, there are some values that can be attributed to the material, and spiritual, and socio-political at the same time. First of all, these are values that have universal significance. Among them are freedom, health, life.

The most relevant problems of modern society are directly related to the spiritual and moral sphere of our being: the absence of the ideological base of meaningful orientation and the socio-cultural identification of students; a change in the mechanism of succession of generations, due to the general disintegration of culture, the erosion of the value basis and the traditional form of public morality; lowering the interest of young people to their national culture, traditions, history, to the carriers of national identity; decrease in the prestige of education as a method of social adaptation, cultural continuity and a form of self-realization of a person; low student activity in solving local, regional, national problems (Abakumova, Ermakov and Kolesina, 2016; Berberyan and Gabrielyan, 2019). As Fromm, E. (2013) notes, a large number of people fluctuate between different value 
Abakumova, I., Berberyan, A. \& Berberyan, H. (2019). Psychological characteristics of the value orientation system of Armenians in title ethnos and Russian diaspora, International Journal of Cognitive Research in Science, Engineering and Education (IJCRSEE), 7(2), 11-17

systems and therefore do not develop fully in a certain direction; such people have neither selfhood nor self-identity. Consequently, values are the core of the structure of personality and they determine its direction, regulate social behavior (Leontiev, 2017).

An important function of values is a prognostic function, since it is based on the development of a certain life position and various life programs, the creation of a plan for the future and the prospects for the development of the personality itself. That is, values regulate not only the present state of the individual, but also its future state; they define its life principles, its ideals, goals, objectives. Values, which act as a person's perception of due, mobilize vitality and abilities of an individual to achieve a specific goal.

\section{MATERIALS AND METHODS}

Participants. A total of 160 bachelor and master students (82 females, age range: 18-25) in Russian Federation and Armenia volunteered to participate in the current study. The participants represented four groups: (1) ethnic Armenians residing in Armenia, (2) ethnic Armenians, residents of Russia, (3) ethnic Russians residing in Russia, (4) ethnic Russians, residents of Armenia. For the descriptive statistics on participants see table 1 .

Table 1. Descriptive statistics

\begin{tabular}{llc}
\hline & Participants & $\mathrm{N}$ \\
\hline \multirow{2}{*}{ Sex: } & Male & 78 \\
\cline { 2 - 3 } Age & Female & 82 \\
\hline & \multicolumn{1}{c}{$22-25$} & 123 \\
\cline { 2 - 3 } & $\begin{array}{l}\text { Ethnic Armenians } \\
\text { in Armenia }\end{array}$ & 56 \\
\cline { 2 - 3 } Residence: & $\begin{array}{l}\text { Ethnic Russians in } \\
\text { Armenia }\end{array}$ & 23 \\
\cline { 2 - 3 } & $\begin{array}{l}\text { Ethnic Armenians } \\
\text { in Russia }\end{array}$ & 38 \\
\cline { 2 - 3 } & $\begin{array}{l}\text { Ethnic Russians in } \\
\text { Russia }\end{array}$ & 43 \\
\hline & Total & 160 \\
\hline
\end{tabular}

Methods. The following methods were used:

\section{Twenty Statements Test}

Twenty Statements Test developed by Kuhn, M. H. and McPartland, T. S. (1954) is a psy-chodiagnostic technique, representing non-standardized self-description, in which the participant responds to an open question.

A participant is given 12 minutes to formulate twenty different answers to the question that is addressed to him: "Who am I?". Answers must be given in the same order in which they spontaneously come to mind. After that, the participant must evaluate each quality as positive or negative, or ambiguous, or use the sign that he is difficult to assess (?). The analysis of identification characteristics includes 24 indicators, the combination of which leads to the formation of seven generalized indicators-components of identity.

\section{Schwartz's Value Survey}

The Schwartz value test is used to study the dynamics of changes in values both in groups (cultures) due to changes in society and for a person due to his life problems. The basis of the Schwarz's questionnaire is the theory that all values are divided into social and individual. The questionnaire consists of two main parts: the first one is designed to explore the values, ideals and beliefs that affect the person (57 values). The second part of the Schwartz questionnaire is a personal profile. In contains a list of 40 descriptions of a person corresponding to one or another of the 10 types of values is given.

\section{RESULTS}

In the title Armenian ethnos, the participants' ideas about a typical Armenian woman and a man are similar in meaningful characteristics to the ideas of an ideal Armenian. In the assessment of men, the following values were highest: loyalty to friendship (4.52), respect for elders (4.29), religiousness (4.29), friendliness (4.20), and independence (4.19) dominate; in the assessment of wom-en, friendliness (4.37), strength (4.24), loy-alty to friendship prevail (4.22), hospitality (4.13), pride (4.07), courage (4.0). The rejected and low-valued qualities of a typical Armenian man are arrogance (1.16), naivety (1.28), rudeness (1.43), in the assessments of women - the ability to laugh at themselves (1.82), daydreaming (1.82), shyness (1.91).

In the assessment of a typical Arme-nian woman, the qualities of tact prevail in men 
(4.22), emotionality (4.19), kindness (4.19), optimism (4.12), religiousness (4.09); in the assessments of women - hospitality (4.34), respect for elders (4.04). There is almost complete coincidence in the assessments of boys and girls of denied qualities: arrogance $(0.46-0.39)$, rudeness $(0.72-0.75)$, thievery $(0.84-0.34)$.

Content analysis of the answers of the Armenian respondents showed that for them the "ethnocultural traditions" factor is the most significant $(59.2 \%$ of the responses of men and $46.2 \%$ of the responses of women), among which the main ones are the native language (10\% and 5\%), compliance customs and approved rules of conduct $(10 \%$ and $4.4 \%)$, features of upbringing in the family $(4.8 \%$ and $3.6 \%$ ), as well as knowledge and active use of folklore traditions (wedding ceremonies, music, dancing) (20, $1 \%$ and $18.4 \%)$. The second important factor is the value system $(22 \%$ of the responses of men and $14 \%$ of the responses of women). This provision emphasizes such a value guideline as the conformity to the national ideal, the need to reproduce, in practical terms, forms of etiquette behavior expressing basic national values, which should contribute to creating a positive image of a representative of the Armenian ethnic group in a different ethnic environment. The third significant factor of self-understanding of ethnocultural affiliation is "ethnic solidarity" (concern for other representatives of the ethnic group, responsibility for the behavior and lifestyle of other Armenians) - $10 \%$ of the responses of men and $19.9 \%$ of the responses of women. Ethnic solidarity, support of compatriots and the formation of a positive image of representatives of their ethnos are of great importance for the Armenian respondents. Awareness of their cultural differences for the Armenian respondents leads to the desire to be worthy representatives of their ethnic group, they realize their own responsibility for shaping the image of a representative of an ethno-cultural community in the eyes of the ethnic majority. At the same time, the Armenian respondents are aware of their belonging to Russia, to the Russian people, therefore, ethnocultural identity in the diaspora is not opposed to civilian, it is recognized as its component, component, which leads to the realization of double responsibility for their actions, their behavior before ethnic group, ethnocultural community and the country as a whole.

At the same time, in the female sample of representatives of the diaspora, in contrast to the male, the idea of a typical and ideal Ar- menian coincides in many ways, significant differences were found only in the assessment of qualities: lack of egoism, lack of tendency to lie, reasonableness, tendency to make the same mistakes, patience, poise, emotionality. Thus, a typical representative of the Armenian ethnos, in the opinion of Armenian girls, is more selfish, emotional and less intelligent than ideally (Berberyan and Gabrielyan, 2019).

The elements of "Self-image", in which there are no significant differences with the qualities of an ideal and typical man, include qualities: loyalty to friendship, conscientiousness, kindness, perseverance, resourcefulness, responsibility, religiousness, decisiveness, independence, restraint, strength, propensity to take risks, tact, respect for elders, stubbornness, as well as rejected qualities: rudeness, laziness, arrogance. There are no significant differences in the conception of oneself and the image of a typical man when assessing the rejected qualities: thiev-ing, arrogance, naivety.

In the female sample, the elements of "Self-image", in which there are no significant differences with the qualities of an ideal and typical woman, constitute the qualities of hospitality, respect for elders and denied qualities of thievery, arrogance, desire for "freebies", rudeness. To the qualities in the evaluation of which there are no significant differences of the "Self-image" with the qualities of an ideal woman, the respondents attributed loyalty to friendship, mutual assistance, willingness to help, good nature, good faith, kindness, friendliness, sincerity, love of order, optimism, responsibility, responsiveness, hard work, diligence mind.

In the conditions of the diaspora, the Armenian youth self-image practically coincides with the idea of a typical Armenian, respectively, men evaluate themselves in the context of normality, which differs significantly from the norm.

On the contrary, the image of themselves among Armenian girls practically coincides with the idea of an ideal Armenian. The significant coincidence of the estimates of the ideal and typical representative of the ethnos, as well as the self-image in the female sample, indicates the desire of girls to reproduce normative ethnocultural patterns. 
Abakumova, I., Berberyan, A. \& Berberyan, H. (2019). Psychological characteristics of the value orientation system of Armenians in title ethnos and Russian diaspora, International Journal of Cognitive Research in Science, Engineering and Education (IJCRSEE), 7(2), 11-17

\subsection{Comparative analysis of the results of Armenians and Russians in title ethnos and diaspora}

According to the results of Twenty Statements Test, the following results were obtained: 1. ethnic Armenians of the titular ethnic group in 38\% use Reflective Self statements when describing themselves, $35 \%$ uses statements related to Social Self, , 2. among ethnic Armenians of the Russian diaspora in $37 \%$ the description appears through Social Self, in 36\% respectively through Reflective Self, 3. 39\% of ethnic Russians of the titular ethnic group use statements related to Social Self, $26 \%$ when describing themselves refer to Reflective Self. 4. Ethnic Russians of the Armenian diaspora in the majority of cases (39\%) use Reflective Self, in 33\% - Social Self. For overview of full results see table 2.

Table 2. The results of Twenty Statements Test for Armenians and Russians in Armenia and Russia

\begin{tabular}{ccccc} 
Self-description & $\begin{array}{c}\text { Armenians } \\
\text { in title } \\
\text { ethnos }\end{array}$ & $\begin{array}{c}\text { Armenians } \\
\text { in Russia }\end{array}$ & $\begin{array}{c}\text { Russians } \\
\text { in title } \\
\text { ethnos }\end{array}$ & $\begin{array}{c}\text { Russians } \\
\text { in } \\
\text { Armenia }\end{array}$ \\
\hline Social & $35 \%$ & $37 \%$ & $39 \%$ & $33 \%$ \\
\hline Communicative & $12 \%$ & $7 \%$ & $11 \%$ & $0 \%$ \\
\hline Material & $6 \%$ & $2 \%$ & $3 \%$ & $3 \%$ \\
\hline Physical & $4 \%$ & $0 \%$ & $1 \%$ & $3 \%$ \\
\hline Active & $5 \%$ & $17 \%$ & $17 \%$ & $7 \%$ \\
\hline Prospective & $0 \%$ & $1 \%$ & $3 \%$ & $15 \%$ \\
\hline Reflective & $38 \%$ & $36 \%$ & $26 \%$ & $39 \%$ \\
\hline
\end{tabular}

Thus, when describing themselves, the majority of participants, both ethnic Armenians and ethnic Russians, predominantly use the statements related to Social Self and Reflective Self. The statements related to Social Self include the use of family identity, civic and ethnic and educational-professional position.

The similarities between representatives of the Armenian titular ethnic group and Armenians residing in Russia were found based on the results of Schwartz value test: harmony (6.5 for Armenians in Armenia and 6.7 for Armenians in Russia respectively), freedom (6.7 and 6.1), the meaning of life (6.1 and 6.0), respecting parents (6.1 and 5.9) were found to be the most significant values; the least significant for both groups were to obey the circumstances (3.1 and 2.3) and submissiveness (3.7 and 3.1). The analysis of the two groups revealed the following differences: the significance of the values "security of the nation" (3.78 and 5.9) and respect for traditions (5.0 and 6.7) was higher for representatives of the Russian diaspora, whereas independence (6.28 and 4.9) and self-confidence (5.1 and 4.0) was higher for representatives of the titular ethnic group.

A correlation analysis was carried out, on the basis of which the following results were obtained:

1. There is a statistically significant rela-tionship between the value orientations of female and male respondents, the significance level is Sig (2-tailed) $=0,000$, Pearson correlation $=0.869$, which indicates a high correlation between these groups.

2. A statistically significant relationship was observed between the results of ethnic Armenians living in Armenia and Russia, Pearson correlation $=0.724-$ a high correlation (Sig < 0.05). Additionally, a correlation was observed for the value orientations of Armenians residing in Russia and Russians residing in Russia 0.497 ( $\mathrm{Sig}<0.05)$, which is an indicator of a connection between the values of these groups.

\section{DISCUSSIONS}

The results of the participants from Armenia allowed us to highlight the similarities between a man and a woman in the respondents' perceptions about themselves, while the rejected qualities are different. These results testify to the similarity in the perception of positive qualities and differences in the perception of rejected, negative qualities of "Selfimage" in the self-understanding of Armenian students.

When comparing the estimates of the typical and ideal representatives of the ethnos by the young men, significant differences were found in almost all the scales, which indicates that the ethnocultural sample and ideas about the real Armenian are opposed in the minds of the respondents. This gap indicates the semantic plasticity and value saturation of the ethnic ideal with the instability of the normative component of the tradition.

When comparing the severity of qualities included in the structure of the "Selfimage" and the images of ideal and typical representatives of the ethnos, significant differences were found in the results of the study of representatives of the title Armenian ethnos and diaspora. 
Abakumova, I., Berberyan, A. \& Berberyan, H. (2019). Psychological characteristics of the value orientation system of Armenians in title ethnos and Russian diaspora, International Journal of Cognitive Research in Science, Engineering and Education (IJCRSEE), 7(2), 11-17

The most significant differences in the value indicators of the residents of Armenia and the Armenian diaspora showed the value of security, which is based on the need for adaptability and predictability of the world, reducing uncertainty. The high significance of security in the value structure of the Armenian title ethnos has historical roots and is also largely due to the complex economic and geopolitical situation of today's Armenia. Values of hedonism (pleasure, sensual pleasure, enjoyment of life), stimulation (fullness of life sensations) and universalism (understanding, gratitude, tolerance and maintaining the wellbeing of all people and nature) are markedly less pronounced in the diaspora than in the title Armenian ethnos. It can be assumed that in the conditions of the Armenian diaspora in Russia, young people form an orientation towards activities that imply high rationality, activity, initiative, and the ability to compete.

The value of power (achievement of social status, prestige and influence on other people) is significantly higher in groups of representatives of the titular ethnic groups (Armenians and Russians) than among representatives of the diaspora. Accordingly, the formation of the values of representatives of the diaspora is influenced not only by the values of the representatives of the title ethnos in whose territory they live, but also the situation of the diaspora itself. The dual challenge facing the representatives of the diaspora: the adaptation to the culture of another ethnos and the preservation of cultural identity, makes less important the value of power and influence on others.

\section{CONCLUSIONS}

The results obtained make it possible to identify common features of the value-semantic aspect of the ethnic identity of a person both within the framework of the Armenian ethnos and different conditions of existence of this ethnic group - the title ethnos and diaspora.

As a result of the study, both general principles and features of the subject's inclusion in the cultural-historical tradition in the process of self-understanding of their ethnicity were identified.

The introduction of the individual to a particular culture is the process of forming an individual and unique system of values. In the process of mastering a culture, an individual is transformed into a personality, since a personality is a person, the combination of prop- erties of which enables him to live in society as a full-fledged member, interact with people around him and realize activities for the production of various cultural objects.

\section{ACKNOWLEDGEMENTS}

Our study was carried out with the financial support of the Russian Foundation for Basic Research (RFBR) (application 2018) within the project titled "Psychological and genetic studies of predictors that determine user behavior in the perception of Internet content of various informational orientation".

\section{Conflict of interests}

The authors declare no conflict of interest.

\section{REFERENCES}

Abakumova, I. V., Ermakov, P. N., \& Kolesina, K. Y. (2016). On analyzing the results of empirical research into the life-purpose orientations of adults of various ethnic identities and religious affiliati. Psychology in Russia, 9(1), 155. https:// doi.org/10.11621/pir.2016.0111

Berberyan, A. S., \& Berberyan, H. S. (2016). Ethnopsychological aspects of the meaning-of-life and value orientations of Armenian and Russian students. Psychology in Russia, 9(1), 121. https:// doi.org/10.11621/pir.2016.0109

Berberyan, A., \& Gabrielyan, R. (2019). Ethnocultural Identity and Values of Leadership Among the Youth. In Sustainable Leadership for Entrepreneurs and Academics (pp. 57-63). Springer, Cham. https://doi.org/10.1007/978-3-030$15495-06$

Fromm, E. (2015). The art of listening. Open Road Media.

Kuhn, M. H., \& McPartland, T. S. (1954). An empirical investigation of self-attitudes. American sociological review, 19(1), 68-76. https://doi. org/10.2307/2088175

Lebedeva, N., Tatarko, A., \& Berry, J. W. (2016). Intercultural relations among migrants from Caucasus and Russians in Moscow. International Journal of Intercultural Relations, 52, 27-38. https://doi.org/10.1016/j.ijintrel.2016.03.001

Leontiev, D. (2017). Converging paths toward meaning. Journal of Constructivist Psychology, 30(1), 74-81. https://doi.org/10.1080/10720537.2015.1 119089

Soldatova, G., \& Geer, M. (2013). "Glocal” Identity, Cultural Intelligence and Language Fluency. Procedia-Social and Behavioral Sciences, 86, 469-474. https://doi.org/10.1016/j. sbspro.2013.08.599

Stefanenko, T. G., \& Kupavskaya, A. S. (2010). Ethno-cultural competence as a component of competence in communication. Psychology in Russia: State of the Art, 3, 550-564. https://doi. org/10.11621/pir.2010.0027

Tajfel, H. (Ed.). (2010). Social identity and intergroup 
Abakumova, I., Berberyan, A. \& Berberyan, H. (2019). Psychological characteristics of the value orientation system of Armenians in title ethnos and Russian diaspora, International Journal of Cognitive Research in Science, Engineering and Education (IJCRSEE), 7(2), 11-17

relations (Vol. 7). Cambridge University Press. https://doi.org/10.1007/978-3-658-13213-2 75

Waterman, A. S. (1982). Identity development from adolescence to adulthood: An extension of theory and a review of research. Developmental psychology, 18(3), 341. http://dx.doi. org/10.1037/0012-1649.18.3.341 